\title{
Paradigmas y estructuras en las comedias triples del Siglo de Oro
}

\author{
Paradigms and Structures \\ in the Triple Comedies of the Golden Age
}

\author{
Adrián J. Sáez \\ Université de Neuchâtel
}

\section{RESUMEN}

Este artículo analiza una modalidad particular del teatro del Siglo de Oro: las comedias triples o de triple argumento. Se trata de un modelo poco atendido por la crítica dentro del que, según se propone, pueden diferenciarse dos paradigmas: la comedia triple stricto sensu, que une tres historias independientes en un mismo texto; y la comedia tripartita, que muestra tres etapas de un mismo argumento, una por jornada, y que sigue una práctica ya vigente en el teatro renacentista. Mediante el estudio de algunos ejemplos significativos se tratan de justificar las diferencias entre ambos paradigmas y la experimentación de estas estructuras con las unidades dramáticas.

Palabras Clave: Teatro del Siglo de Oro, comedia triple, comedia tripartita, estructura, experimentación dramática.

\section{ABSTRACT}

This article analyzes a particular form of the Golden Age Theater: the triple comedies or of triple argument. It is a model that has been very little studied by the critics inside of which, as I tray to prove, can differ two paradigms: the triple comedy stricto sensu, which links three independent stories in a same text; and the tripartite comedy, which shows three steps of the same argument, one by act, and which follows an antique practice valid in the Renaissance Theater. Through the study of some significant examples, I try to justify the differences between both models, in which the poets experiments with the dramatic unities.

Key words: Theater of the Golden Age, triple comedy, tripartite comedy, structure, Calderón de la Barca.

Una modalidad escasamente atendida en los estudios sobre teatro áureo son las comedias triples o de triple argumento, que en un primer momento pueden definirse como un tríptico dramático que representa tres argumentos distintos — por lo general independientes en origen - enlazados en una misma comedia. La mayoría de las obras que pueden clasificarse dentro de este subgé- 
nero - cuyo repertorio y trayectoria quedan por establecer- son bien conocidas y gozan de solventes ediciones y estudios, pero carecen, en contrapartida, de una consideración conjunta en tanto modalidad estructural particular del patrimonio teatral clásico español. No obstante, esta peculiar apuesta dramática no es uniforme, y pueden señalarse dos paradigmas diferentes según el diseño de su estructura y arquitectura dramáticas, como se verá. En las páginas que siguen se pretende abordar algunos ejemplos significativos en orden puramente didáctico, como un primer paso para profundizar en el reconocimiento y análisis de esta peculiar forma dramática.

\section{COMEDIA TRIPLE: LAS TRES COMEDIAS EN UNA}

El primer modelo es el que puede considerarse canónico en este subgénero de las comedias de triple argumento. Constituye una mixtura - que no mezcla- de argumentos diferentes e independientes, pero fácilmente vinculables por diversos motivos, que se desarrollan como líneas de acción paralelas en la comedia. Igualmente, puede darse que prime uno de los argumentos en cada jornada, o que se dramaticen a la par para concluir al unísono en el final. En juego con un título calderoniano, podría denominarse el caso de «las tres comedias en una».

Requisito imprescindible es que las historias dramatizadas sean conocidas, al menos a grandes trazos, para que la selección de episodios y fragmentos no derive en una carencia informativa que dañe la comprensión cabal de la comedia. Esta es la razón por la que estos textos tripartitos son con frecuencia de asunto mitológico o hagiográfico (entiéndase aquí con el sentido amplio de 'religioso' sin entrar en consideraciones genéricas). Así, su lectura o visualización requiere de una participación activa por parte del receptor, quien debe reconstruir o suplir las lagunas de los hilos sacados de diversos husos para alumbrar el tapiz completo.

Precisamente, dicho entrelazamiento de historias puede resultar perjudicial para la trabazón de la comedia, ya que puede dar la impresión de carecer de unidad estructural. Así pues, el dramaturgo debe ser muy cuidadoso a la hora de escoger los relatos (y sus secuencias) que va a hilvanar, para que los puentes que tienda entre ellos no se desmoronen con facilidad.

1. Comienzo por Los tres mayores prodigios (Calderón de la Barca, 2007b), una de las fiestas palaciegas representadas en la noche de san Juan de 1636 y broche de oro de la Segunda parte de comedias del poeta, publicada en $1637^{1}$. Reúne a una tríada de grandes héroes clásicos: Jasón, Teseo y Hércules, cada uno de los cuales reaparece en otras piezas de Calderón ${ }^{2}$. Los

\footnotetext{
${ }^{1}$ Ver Fernández Mosquera (2006, 2007 y 2008).

${ }^{2}$ El primero en el auto El divino Jasón (Calderón de la Barca, 1992); el segundo en dicha pieza sacramental (como san Andrés), en El laberinto del mundo y en Fortunas de Andró-
} 
tres se presentan unidos ya en la loa de la comedia, de gran importancia para la interpretación de la obra: el personaje de la Noche avanza el argumento de la comedia en diálogo con las ninfas Pales y Flora, situadas en los escenarios de derecha e izquierda. En el tablado central se halla Hércules, quien refiere a Jasón y Teseo el rapto de Deyanira a manos del centauro Neso y solicita su ayuda para recuperar a su amada: Jasón recorrerá Europa en la nave Argos, Teseo explorará Asia a caballo y Hércules África, todos con un año de plazo $^{3}$. Al comienzo de su relato Hércules explicita la relación entre los héroes:

los tres en tantas ocasiones tres almas, vidas tres, tres corazones en solo uno fundimos y con uno no más los tres vivimos (Calderón de la Barca, 2007b: 996).

Según es habitual, el hilo conductor que enlaza a los tres es el amor: la tristeza de Hércules da inicio a la búsqueda del raptor de Deyanira, en cuyo transcurso Jasón y Teseo se encontrarán con Medea y las hermanas Ariadna y Fedra. Debe recordarse también que, más adelante en estos relatos míticos, las mujeres resultan fatales para los héroes: cuando Jasón se separa de Medea para casarse con Glauce, ella mata a su rival y a sus propios hijos antes de regresar a la Cólquide (Apolodoro, 1985: I, 9, 28), tragedia que en algunas versiones da lugar a la muerte del argonauta; y Deyanira es la responsable de la muerte de Hércules, sustituyéndose los celos por el romance del héroe con Yole. Por su parte, Teseo rompe su compromiso con Ariadna a favor de Fedra, a quien ama, pero ninguna de ellas será el origen de sus desdichas ${ }^{4}$. Ahora bien, dado que el amor de Jasón y Teseo surge durante sus aventuras, la clave que explica la subordinación de sus peripecias al rescate de Deyanira es que, como bien dice Rull (2012: 163), la empresa de Hércules supone una «mayor abnegación moral» ${ }^{5}$, aunque su condición de héroe por antonomasia tampoco debe pasarse por alto.

La Noche cierra la loa con una síntesis de lo que sigue:

meda y Perseo; y el tercero en el auto citado (san Pedro), en Fieras afemina amor y en una representación metadramática en Las manos blancas no ofenden. Ver la tabla final pero incompleta de Neumeister (2000: 314-315). Sobre Teseo, Moraleda (1988) compara El Perseo, de Lope y con Fortunas de Andrómeda y Perseo, de Calderón. Inciden en ello Martínez Iniesta y Martínez Bennecker (2009), quienes suman un contraste entre El laberinto de Creta, de Lope, con la segunda jornada de Los tres mayores prodigios, respectivamente; opinan que Calderón parte de Lope pero que esta vez no logra perfeccionar su base: la reducción a una jornada de la historia de Teseo resta brillantez a la fábula. Para Jasón en el auto ver Rull (2012).

${ }^{3}$ En Fortunas de Andrómeda y Perseo también cambia la situación geográfica en cada jornada: Acaya, Trinacria y África. Cito por las ediciones fichadas en la bibliografía final.

${ }^{4}$ Jasón y Teseo, además, se enmarcan junto a Ulises y Orfeo como los héroes míticos que pueden servir de ejemplo «para la aventura singular de cada hombre» en el auto sacramental (Suárez Miramón, 2011: 350).

${ }^{5}$ Ver también los comentarios de Rull (2005). 


\begin{abstract}
Esta división que han hecho estos tres héroes valientes de las tres partes del mundo, adonde a los tres suceden tres maravillas, en tres teatros por tres diferentes autores son la comedia que aquesta noche ha de verse. Un corto ingenio la ha escrito, si bien por disculpa tiene sus mismos errores, pues con lo que yerra obedece; y pues a la novedad algún aplauso se debe, pedidle las dos, pues sois a quien festejar compete en retiros y jardines tanto generoso huésped (Calderón de la Barca, 2007b: 1004-1005).
\end{abstract}

Si la primera parte de este parlamento incide en la estructura triple, en la segunda puede verse una referencia a las disposiciones previas para la composición de la comedia, pues Calderón no se libraba de los «continuos requerimientos por parte de quienes estuvieron implicados con él en la confección de las fiestas reales», según Lobato (2001: 188) ${ }^{6}$. Tal vez la unión de tres historias clásicas, si no procedía de arriba — que no creo-, trataba de cumplir con las características especiales (escenario triple, tres compañías de actores...) que le habían solicitado o impuesto para la celebración del momento ${ }^{7}$. En tal caso, la invención de reunir tres historias en una sola podría enmarcarse dentro de la defensa de la palabra poética de Calderón frente al triunfo de la tramoya.

A partir de aquí la búsqueda de Deyanira funciona como el nexo o la excusa que permite a Jasón y Teseo arribar a la sede donde realizar sus más célebres hazañas: lograr el vellocino de oro y matar al Minotauro en el laberinto de Dédalo, ambos con la ayuda de una mujer que los ama, Medea y Ariadna. Ambos refieren el motivo de su llegada a Colcos y Creta, pero nada más, para pasar a centrarse en sus acciones, referidas in medias res y retocadas libremente por el poeta. Baste apreciar que Teseo parte de Creta con Fedra, dejando allí mismo a Ariadna, sin viajar con ella hasta la isla de Naxos donde cuenta la tradición que fue abandonada por orden de Dionisos. El ritmo de la representación de los elementos seleccionados de los mitos es vertiginoso, acuciado por las limitaciones de una jornada para cada historia ${ }^{8}$.

Ya en la tercera jornada protagonizada por Hércules, tras vencer a Neso y recuperar a Deyanira, sus aliados regresan sin haber cumplido su cometido mas coronados en otras lides. Esta jornada es la suma de las anteriores: se unen los

\footnotetext{
${ }^{6}$ Ver también Lobato (2003) y Fernández Mosquera (2008).

${ }^{7}$ Recuérdese el episodio de El mayor encanto, amor, en el que Calderón se enfrentó a la memoria de apariencias ideada por Cosme Lotti, activo en España entre 1626 y 1643. No consta, sin embargo, su participación en la escenografía de Los tres mayores prodigios, aunque se conserva un elogioso testimonio del embajador inglés Aston sobre su puesta en escena (reproducido en Fernández Mosquera, 2008: 221-222, n. 34). No atiendo a los juegos en perspectiva y otros usos de maquinaria y escenografía.

${ }^{8}$ De hecho, Martínez Iniesta y Martínez Bennecker (2009) afirman que en la segunda jornada «la historia discurre de forma precipitada, pues el asunto está muy constreñido, ya que en tan corto espacio de tiempo Calderón quiere escenificar los hechos esenciales de la leyenda cretense del héroe, por lo que tiene que sacrificar, además de las historias paralelas, tan convenientes para agilizar la fábula, elementos sustanciales de la acción. De ahí que el principio resulte demasiado abrupto y poco justificado».
} 
tres escenarios que estaban separados desde la acotación inicial (Calderón de la Barca, 2007b: 1121), justo a tiempo para asistir a la muerte de Hércules y a la inmolación de Deyanira. Es una interesante experimentación fabulística y escénica, pero todavía presenta una unión poco elaborada. Afirma Rull:

la obra está constituida por un verdadero tríptico, en el que el panel central corresponde a la historia de Hércules, y los laterales a las de Jasón y Teseo, respectivamente, aunque también podría verse la obra de forma circular: la historia de Hércules abrazaría a las otras dos, que acabarían y empezarían en ella (2012: 153).

Poco después incide en la importancia de los cuatro elementos en la disposición de la comedia y defiende su «unidad estructural férrea, aunque la apariencia es la de la acumulación de episodios» (Rull, 2012: 155) ${ }^{9}$. Sin embargo, considero que la interrelación de las tres historias no pasa de ser poco más que una yuxtaposición, por muy «perfectamente calculada y organizada» que esté, a lo largo de un hilo dramático constante. O, si se prefiere, el equilibrio entre la unidad de la acción, del argumento central, se resiente con los episodios aventureros de cada héroe en solitario. El armazón del edificio dramático está soldado mediante un débil vínculo que ya se aprecia en la tripartición de los repartos de personajes y de las tablas. Las tres historias, supeditadas a la central de Hércules, funcionan de modo bastante autónomo después de su presentación inicial en la loa: cada hazaña ocurre en una de las jornadas, con uno de los héroes como figura protagónica y no es hasta el final de la tercera cuando vuelven a concurrir sobre las tablas.

2. Más desarrollada y lograda es la trabazón argumental y estructural en $L a$ fiera, el rayo y la piedra (1652) (Egido, 1989b: 11) ${ }^{10}$. En una sola comedia Calderón ha reunido los amores de Pigmaleón y su estatua, Ifis y Anajarte, y Céfiro e Irífile. Los dos primeros son de inspiración ovidiana (Metamorfosis, X, 143-297; XIV, 695-764), mientras el tercero nace de la inventiva del poeta ${ }^{11}$. Sobre todos

${ }^{9}$ Luego deja traslucir una falla en la unidad global: «esta historia [la de Jasón], tal como la entiende Calderón en Los tres mayores prodigios, está supeditada a la historia trágica de Hércules. Más parece como si el dramaturgo hubiera sentido la necesidad de hacer un drama independiente de ella (antes o después de la misma, eso no cambia nada), que es lo que se propuso decididamente en el auto sacramental El divino Jasón» (157-158).

${ }^{10}$ Escrita para la celebración del cumpleaños de la reina Mariana de Austria, esposa de Felipe IV. Egido (1989b: 11) apunta que pudo ser escrita un año antes, en 1651. El resto de las dataciones procede de las ediciones manejadas.

${ }^{11}$ Recuérdese la traducción de las Metamorfosis (1589) de Pedro Sánchez de Viana, más las interpretaciones morales de Pérez de Moya (Filosofía secreta de la gentilidad, 1585) y Vitoria (Teatro de los dioses de la gentilidad, 1620 y 1623). Céfiro o Favonio era el dios del viento de Occidente: es personaje de Apolo y Climene, donde tiene un amorío con Flora, siguiendo a Ovidio (Ovidio, 2005). Hoz (1988: 57-58) asegura que la historia de Anajarte no es propiamente un mito, «sino una historia sentimental helenística, quizá puramente ovidiana». Esta temible mujer aparece luego en Dicha y desdicha del nombre, mientras Irífile actúa en Duelos de amor y lealtad. Una negra se llama Irífile en La sibila del Oriente, pero no guarda relación con la dama de este texto. 
ellos planea el duelo entre Anteros y Cupido, el amor correspondido frente al esquivo. Pero no queda ahí: otros personajes y motivos clásicos con menor relevancia en el drama son las Parcas, la fragua de Vulcano, Venus, Anteo, etc. La materia mitológica constituye el cañamazo para la creación de Calderón, quien no permanece fiel a ninguno de los relatos que toma, sino que los modifica para tejer un tapiz con las tres historias de amor principales, ya explícitas en el triple título y recurrentes a lo largo de sus más de 3.000 versos.

La dificultad de la pieza radica en ensamblar tres historias sin conexión en origen, aparentemente desligadas, que además rompen tajantemente con la unidad de acción aristotélica. Para ello, Calderón inserta la materia mitológica en los moldes de la comedia nueva. Como bien aprecia Egido (1989b: 55-56 y 70), este entrelazamiento de las intrigas amorosas de tres duetos de caballero y dama, con sus conflictos derivados, es similar a una «compleja comedia de enredo», con resortes propios de un género ya codificado.

Las modificaciones de las fábulas originales son, pues, de mayor calado que en Los tres mayores prodigios. Así, la isla de Sicilia es el único espacio elegido, cuando los relatos de Pigmaleón y Anajarte sucedían en Chipre. Los cambios se suceden: para establecer las correspondencias, el dramaturgo ha convertido a Anajarte en princesa heredera al trono de Sicilia, cargo que en realidad corresponde a Irífile, oculta en los montes para evitar el cumplimiento de un oráculo; igualmente, nombra rey de Epiro a Ifis y silencia su desgraciada muerte para cumplir con su diseño poético. A su vez, el episodio de Pigmaleón se traslada de Libia a Trinacria, y no consta que él sea el artífice de la escultura de la que se enamora, de modo que se suprime un elemento fundamental del tema tradicional: «esa especial relación anormal y casi incestuosa entre lo animado y lo inánime, entre el creador y la criatura» (Cristóbal, 2003: 73); la adoración a un objeto causa los celos de Anajarte, quien manda expulsar la estatua de su jardín, abriendo camino a que Pigmaleón construya el palacio donde confluirán todos los personajes y se atarán todos los cabos de la comedia.

Esta tríada de historias y conjuntos de figuras ofrece un movimiento casi constante en la escena (Egido, 1989b: 59): los tres galanes se cruzan, oponen $\mathrm{y}$ favorecen en sus pretensiones amorosas y finezas hacia sus damas, quienes también interactúan entre sí, en un campo de batalla partido entre el amor y el desdén, la correspondencia y los celos. Por tanto, puede decirse que esta triple intriga queda acompasada al ritmo que marca la dialéctica entre los dos hijos de Venus y que acaba en dos felices bodas (Céfiro e Irífile, Pigmaleón y la estatua) más el castigo a las durezas de Anajarte. Según aprecia Cristóbal (2003: 73), la correspondencia entre las dos metamorfosis procede de Calderón, pues en el texto ovidiano no había contigüidad que manifestara «tal simétrica disimetría»: la mujer que rechaza el amor se transforma en roca, mientras la estatua digna de amar se transmuta en mujer. Ifis queda cual galán «suelto», pero también cabe entender que la metamorfosis en piedra de su 
amada es la venganza por los desdenes recibidos, como declara el propio Anteros (Calderón de la Barca, 1989: 65).

Desde luego, tal alarde de variedad y unidad haría las delicias del senado, favorecido por el despliegue de recursos escenográficos que convierten el tablado en «topografía múltiple» (Egido, 1989b: 63-64). Porque en este caso ya no hay tres escenarios divididos, sino un escenario tridimensional en perspectiva diseñado por Baccio del Bianco que se irá complicando con el paso del tiempo y las sucesivas representaciones ${ }^{12}$.

3. También especialmente lograda me parece la comedia Los tres portentos de Dios (1635-1640) de Vélez de Guevara (2011), fechada entre las dos comedias calderonianas ya comentadas ${ }^{13}$. Se trata de una comedia de santos que dramatiza la conversión del pecado a la vida cristiana y/o la santidad de María Magdalena, Dimas y Saulo. Un trío de grandes pecadores, encarnación individual de un vicio: la concupiscencia típicamente femenina en la época, el robo y la persecución de la fe verdadera. Tal como aprecia Rodríguez López-Vázquez (2011: 22 y 36), la apuesta estética y ética de Vélez consiste en reunir en la misma comedia a tres llamativos ejemplos de conversión milagrosa; pero no son mártires al uso, sino «casos ejemplares por el vuelco que la fe cristiana introduce en sus vidas» y, conjuntamente, la victoria del amor sacro sobre la pasión profana. Además, en la larga fortuna dramática de la penitente Magdalena se documentan diversos casos en los que actúa junto a Dimas o Saulo, cuyo máximo exponente sería El vaso de elección y piedra de la Iglesia atribuida a Lope, lo que tal vez apunte a que Vélez revisase un texto anterior, según explica (2011: 23-28).

Vélez une las tres historias mediante su inserción en el esquema de una comedia de capa y espada: Saulo es el galán que corteja a Magdalena y su criado es Dimas, un gracioso con asomos de pícaro. Los tres portentos de Dios se construye mediante la trasposición «a lo divino» de lo que es «una comedia urbana de enredo amoroso y ámbito temporal histórico» porque no se guía por «ningún guión canónico de Flos sanctorum» sino que «traslada a lo divino un enredo humano» (Rodríguez López-Vázquez, 2011: 28). Esta mezcla de elementos más allá de las barreras genéricas, la inserción en este caso de varias historias sacras en moldes dramáticos codificados, dificulta todavía más la clasificación de un corpus tan vasto y complejo como las comedias de santos, aunque siempre debe tenerse presente que la combinación de ingredientes y tonos dispares es característica del teatro del siglo XVII ${ }^{14}$. Por tanto, es-

12 Ver Egido (1989a y 1995).

${ }^{13}$ Sobre las relaciones entre Vélez y Calderón ver Sáez (2013), con la bibliografía oportuna.

${ }^{14}$ Rubiera (2013) analiza los «lances de capa y espada» presentes en la comedia hagiográfica de Calderón; agradezco su gentileza al enviarme su texto. Señala Rodríguez LópezVázquez (2011: 15): «la propuesta doctrinal de Vélez resulta especialmente problemática para encajar en la tradición, ya que no obedece al principio de ilustración hagiográfica de obras 
tas comedias pueden juzgarse como rasgos de experimentación en una dramaturgia que se renueva constantemente. Y junto a todo ello no puede olvidarse que la comedia de Vélez entraña una lección religiosa, teológica.

Para lograr la audacia de concebir una comedia amorosa con lección moral y habitada por personajes de la tradición bíblica, Vélez congrega sobre la escena tres conversiones que sucedieron en tres momentos históricos distintos. La tríada de personajes comienzan a interactuar desde el principio de la comedia, pero se reparten el protagonismo de modo que cada uno vive su particular proceso de conversión en una jornada. Es más, la triple relación se reitera durante toda la comedia y los arrepentimientos se configuran a modo de exempla para los personajes que todavía perseveran en el pecado, hasta que todos se juntan en la apoteosis final. Así, aunque cada uno posee cierta unidad propia, la estructura global no resulta dañada.

Al principio de la comedia Saulo regresa a Jerusalén desde Tarso (o Tarsis) y el relato de Dimas sobre la belleza de Magdalena despierta el deseo de conocerla. En esto, aparecen Dorcas, Barrabás y Gestas, ladrones compinchados con Dimas para robar a Saulo y asaltar los aposentos de Magdalena, y son derrotados heroicamente por Saulo, quien a la mañana siguiente visita a la dama. Junto a otros pretendientes le acompaña a ver a Jesús, momento en que la pecadora es consciente de sus agravios al cielo y se arrepiente (Vélez de Guevara, 2011: vv. 869 y ss.): se despoja de sus galas, renuncia a los deseos mundanos y a los placeres, etc., siguiendo a Cristo en el camino hacia Dios. Esta es la primera conversión, espejo cuyos reflejos influyen en el resto de la pieza.

En la segunda jornada Dimas relata cómo los galanteos de Saulo no hacen mella en Magdalena, por lo que decide volver a Tarso. La cuadrilla de ladrones es apresada y Saulo se introduce en la casa donde Magdalena se aloja en Betania cuando ella duerme. Pero mientras él trata de gastar sus últimas municiones y rendirla a su amor, ella le anima a que emplee sus fuerzas en servir al cielo. Acaba la jornada con el relato de Saulo de la escena de la Crucifixión, en la que Dimas pide perdón por sus crímenes (Vélez de Guevara, 2011: vv. 1585-1730), segundo portento que no es capaz de entender ni de relacionar con su propia existencia.

La tercera jornada presenta a Saulo como capitán de la persecución de cristianos en Jerusalén. Ni los avisos de Magdalena ni la visión del arcángel Gabriel, que le impide conocer a María al ser peor enemigo de Cristo que Herodes (Vélez de Guevara, 2011: vv. 2091-2118), bastan al pertinaz pecador para apreciar la verdad y persiste en acabar con los cristianos. El camino a Damasco es el momento en que la divinidad debe intervenir para devolver-

bíblicas. En este sentido el concepto de «comedia a lo divino» resulta más apropiado para entender la dramaturgia de la obra, en la que los personajes actúan movidos por conflictos y pasiones humanas dentro de un marco que se proyecta sobre contenidos relacionados con la divinidad». 
le al camino recto. Se trata de la célebre jornada en la que la caída del caballo causa la conversión de Saulo, enemigo de la ley de Dios, en Pablo, vaso de elección para la Iglesia. Tras ello el nuevo personaje se arrepiente animado por la voz de Jesús, ante la visión de la Gloria donde se hallan Dimas y Magdalena con la cruz. Su misión en Damasco será proclamar el cristianismo, como el tercero de «los tres portentos del cielo, / los tres prodigios de Dios» (Vélez de Guevara, 2011: vv. 2421-2422).

La perfecta imbricación de las tres historias no requiere de escenarios divididos ni está adornada con lucimientos escenográficos, más allá del final espectacular. El triángulo amoroso inicial, propio de una comedia de capa y espada, evoluciona a partir de la conversión de Magdalena a un camino que se orienta al amor divino, al conocimiento que da acceso a Dios y cuya dirección no conoce Saulo hasta los últimos versos. La gradación es fácilmente apreciable: Magdalena se convierte durante la predicación de Cristo, Dimas en su muerte y Saulo solo lo logra después, cuando Jesús le habla desde las alturas. Pero reitero: las tres historias nacen y acaban unidas, si bien alcanzan progresivamente su cima.

\section{TRÍPTICO DRAMÁTICO: UNA HISTORIA EN TRES JORNADAS}

El segundo arquetipo principal se asimila más con el molde de las comedias al uso. Produce la falsa impresión de mostrar tres comedias en una, pese a situarse en un nivel muy diferente: no es una comedia triple, sino una comedia tripartita en el sentido más recto de la expresión. La diferencia con las tres historias reunidas en una misma obra dramática radica en que aquí se muestran varias etapas de un mismo argumento, una por jornada. Su autonomía, por tanto, juega con la unidad de acción, de modo similar a algunos ejemplos del teatro anterior. Así, en el prólogo de La gran Semíramis (h. 1580) Virués identifica los tres actos de la tragedia como módulos autónomos:

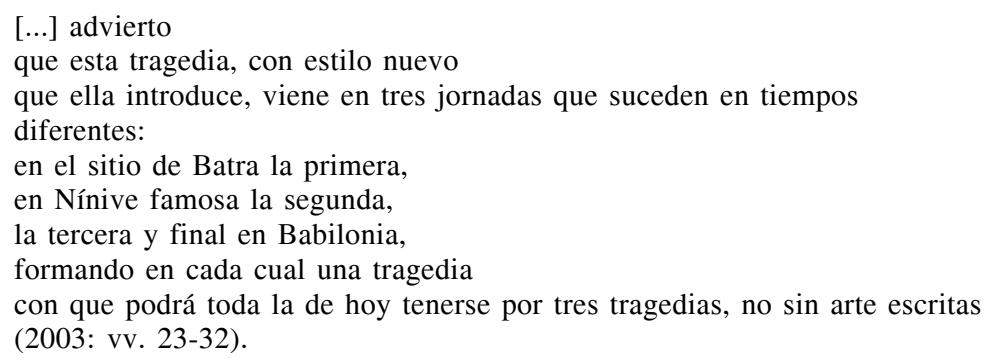

Ha de quedar clara la diferencia existente con una comedia canónica que, obvio, también se estructura en tres jornadas: no se trata de que las unidades de tiempo y lugar no se respeten rígidamente en favor del criterio de verosi- 
militud, que permite asistir al nacimiento de un príncipe, sus hazañas posteriores y su muerte final, con mutaciones espaciales ${ }^{15}$. El modelo que analizo fragmenta la temporalidad histórica, y se sitúa a caballo entre las piezas anteriores que unen tres historias en un conjunto uniforme y el esquema habitual de una comedia con la común división en tres jornadas. Y aunque algunos prefieran la denominación «trilogía» (Romanos, 1998a y 1998b; Calvo, 2002), pueden definirse más propiamente como trípticos dramáticos ${ }^{16}$.

En este contexto el grado de popularidad de la fábula no es ineludible, porque se presenta el todo de la historia y no solo la parte seleccionada. Esto es, el hilo que une la acción de las tres jornadas procede del propio argumento, vivo durante diferentes períodos históricos, y no es fruto de la imaginación del poeta, como en el esquema anterior.

1. Es el caso de la comedia Origen, pérdida y restauración de la Virgen del Sagrario, fechada tempranamente en 1616-1629 (Calderón de la Barca, 2007a) ${ }^{17}$. Fernández Mosquera (2007: LXXX) ya la relacionaba con otra de las comedias de Calderón tratadas, Los tres mayores prodigios: plantea una relación directa entre ambas piezas por «su diseño en tres jornadas que desarrollan tres historias diferentes interrelacionadas, si bien Los tres mayores prodigios lleva a las últimas consecuencias este reparto» (LXXIX). En efecto, tal vinculación existe, pero hay una notable diferencia entre ambas comedias de la Segunda parte, que también apunta: la comedia dramatiza la historia de la Virgen en tres jornadas y «se mezclan tres diferentes momentos de la historia de España en los que tuvieron lugar precisamente el origen, la pérdida y la restauración de la Virgen; por ello también es titulada Las tres edades de España: reino visigodo de Toledo, invasión musulmana y reconquista» (p. XLVIII) $)^{18}$.

${ }^{15}$ Ejemplo tomado de Ricardo de Turia, «Apologético de las comedias españolas», en Sánchez Escribano y Porqueras Mayo (1972: 179). Así pues, no entran en el esquema comentado aquellas comedias «episódicas» (en el sentido aristotélico) como El rufián dichoso de Cervantes, Las mocedades del Cid de Guillén de Castro, La aurora en Copacabana de Calderón o El vengador de los cielos y rapto de Elías de Bances Candamo (2012; manejo la edición de Álvaro Rosa), que, eso sí, no pueden criticarse por atentar contra la unidad de acción, sino que deben definirse como «comedias no unitarias bien hechas», según me comenta Luis Galván (GRISO-Universidad de Navarra). En dichos textos se suceden distintas etapas de una historia, pero permanecen los personajes (Cristóbal y otros, Rodrigo y Jimena, Yupangui y Guacolda, etc.) y los saltos temporales son muchos más reducidos, amén de otras diferencias.

${ }^{16}$ Romanos analiza El primer rey de Castilla, El último godo y La campana de Aragón de Lope de Vega. Esta etiqueta suele emplearse para designar a un conjunto de tres obras que constituyen una unidad, ya sea porque comparten un enlace argumental $-\mathrm{O}$ de otra índoleo porque son del mismo ingenio, como ocurre con la Trilogía de los Pizarro de Tirso de Molina.

17 Valbuena Prat (1989: 41) considera que se trata de una comedia juvenil, idea todavía vigente. Valbuena-Briones (1980) la situaba entre 1617-1619, de modo que sería la primera obra de Calderón. Ver Marcello (2004), Ulla Lorenzo (2007 y 2008). Para Calvo (2002) es su primera comedia sobre la historia de España.

${ }^{18}$ Título que consta en dos sueltas de la BNE (T/55309/7 y T/55360/58), descubiertas por Vega García-Luengos (2002: 47). 
Historia y religión aparecen íntimamente entrelazadas: en efecto, en la primera jornada se explica el origen de la Virgen del Sagrario, con especial atención a la defensa que san Ildefonso hace de la Inmaculada Concepción contra los herejes pelagianos, así como su santificación e imposición de la casulla; en la segunda, los godos han sido derrotados por los árabes y Toledo debe rendirse, no sin antes ocultar la sagrada imagen; finalmente, en la última jornada se presenta la reconquista de la ciudad por Alfonso VI y el encuentro de la Virgen.

Por lo tanto, no hay tres historias en una, no se reúnen tres relatos independientes en una misma comedia: se trata de una sola historia desarrollada a lo largo de varios siglos, desde el período visigótico (s. V) hasta la recuperación de Toledo (1085). Su única cohesión estructural procede de la sucesión de los hechos seleccionados, en un largo recorrido que expone un concepto providencialista de la historia (Calvo, 2002: 124-132). Claro que las jornadas funcionan con una cierta autonomía, como indica ya el reparto triple, pero quiero destacar que no son tres historias con vida propia, sino tres destellos o subacciones de un mismo recorrido (las peripecias de la imagen de la Virgen del Sagrario), una «micro-trilogía» de tres momentos autónomos por personajes, tiempo y acción, en palabras de Marcello (2004: 79).

No hay una mixtura y modificación de tres fábulas al servicio de un designio artístico; en su lugar se representan tres momentos o episodios clave de un único argumento. Según Aparicio Maydeu (2000: 45), esta «concepción autónoma de cada jornada como una pieza independiente, estructurada con las otras dos en forma de correlación», se relaciona con formas parateatrales de la fiesta barroca, como «los pasos procesionales en sucesión argumental o la ceremonia dramatizada del planto de vía crucis», proximidad que atribuye a su temprana redacción ${ }^{19}$. Concretamente, esta comedia mariana reproduce un elemento propio de las ceremonias religiosas por jornada: el altar de la Virgen, el carro triunfal y la procesión final. Así, junto a algunos precedentes estructurales, se puede mantener que se trata de un modelo dramático abandonado (Calvo, 2002) o una «técnica tenida por antigua en Calderón», en palabras de Fernández Mosquera (Fernández Mosquera, 2007: XLVIII).

Ahora bien, quede claro que se trata de una práctica muy dispar de la empleada en Los tres mayores prodigios, La fiera, el rayo y la piedra o Los tres portentos de Dios. Tampoco se pase por alto que la trama procede de las diferentes crónicas y relaciones de los avatares de la Virgen, entre las que destaca el poema Sagrario de Toledo de José de Valdivielso. Calderón preci-

\footnotetext{
${ }^{19}$ Acaba: «El juego escenográfico con formas parateatrales del ámbito litúrgico ayuda a perfilar el natural hibridismo de la comedia religiosa del siglo XVII, a la vez que contribuye a enredar definitivamente la madeja de la recepción del teatro de propaganda fide» (Maydeu, 2000: 754-755). Valbuena-Briones (1980: 753) considera que el himno final puede considerarse un rasgo primitivo que lo relaciona con el teatro escolar. Estos elementos aparecen en otras piezas calderonianas como La aurora en Copabacana, por ejemplo.
} 
sa consultar las versiones de un mismo hecho, mientras que las otras tres comedias nacen de la combinación de fuentes de diversas tradiciones para que, merced al ingenio, se enhebren las distintas fábulas entre sí.

2. A este modelo pertenece Los triunfos de san Miguel de Cubillo de Aragón (2014), publicada en la miscelánea El enano de las Musas (Madrid, María de Quiñones, 1654). Se trata de una comedia hagiográfica con trazas de auto sacramental que dramatiza tres victorias de San Miguel sobre Luzbel: el fratricidio de Caín, la conversión de los pecadores de Nínive y la coronación del rey Bamba, etapas en las que cambian espacio, personajes y tiempo. Traza así una historia de la humanidad a través de un retablo formado por tres cuadros engarzados sólo por las victorias del arcángel (Profeti, 2008: 245).

3. Una última muestra es la Comedia de Nuestra Señora de Guadalupe y sus milagros (1601) de Diego de Ocaña (2010). Se trata de una pieza de estructura algo irregular y sin ninguna división, pero con distintas estrategias para cambiar de tiempo y lugar: tras los milagros en Roma (año 600) se traslada la talla de la Virgen a Sevilla, desde donde tendrá que ocultarse ante la pérdida de España por el rey Rodrigo (711); esta primera parte acaba con un entremés insertado en la acción que enlaza directamente con la recuperación de la imagen y la protección que brinda a las tropas de Alfonso XI en la batalla del Salado (1340).

\section{ARGUMENTO Y ESTRUCTURA: A MODO DE CONCLUSIÓN}

Acaba aquí este acercamiento a algunos ejemplos de comedias triples, que en un análisis permite apreciar una apuesta dramática de singular originalidad en el contexto de la comedia áurea. Pueden apreciarse dos paradigmas, según he tratado de sugerir: las comedias triples stricto sensu que entrecruzan tres historias o fábulas en un mismo texto; y los trípticos dramáticos, que dramatizan tres fases de un mismo argumento, cuyo desarrollo requiere de un momento histórico diferente por jornada y que sigue una práctica ya añeja. Si se permite un símil de altos vuelos, el primero es una trinidad dramática mientras el segundo es un armazón más trino que uno.

El abanico temático abarca argumentos hagiográficos, históricos y mitológicos, cuyo grado de celebridad hace factible la selección y elaboración de elementos al servicio de las intenciones literarias. La galería de mecanismos, paralelismos y estructuras que presentan estas comedias triples $-\mathrm{y}$ me refiero especialmente al primer modelo - pueden considerarse innovaciones con la unidad de acción, en la estela de los versos del Arte nuevo (2011: vv. 181187 ) en los que Lope permite la pluralidad de acciones siempre que no sea episódica, añadiendo otro renglón a un debate muy antiguo que arranca en la Poética de Aristóteles. La búsqueda de la unión entre tramas de origen y tradiciones diversas puede entenderse entonces como intentos de experimentación y renovación de los esquemas dramáticos existentes. 
Así pues, las comedias triples donde se dan cita tres argumentos independientes requieren de una labor de reconstrucción o modificación mayor por parte del dramaturgo, cuyo ingenio toma el mando para que la materia resultante resulte verosímil. Por el contrario, una comedia tripartita como Origen, pérdida y restauración de la Virgen del Sagrario puede calificarse de transposición o reescritura —usando la voz con cierta amplitud- de un único argumento, por muy larga cronología que posea. Y con un pie en cada bando, muy consciente de su arte, Calderón fue capaz de recrear y perfeccionar los dos modelos, en un camino que va de las primeras tentativas a la coherencia.

\section{BIBLIOGRAFÍA CITADA}

Aparicio Maydeu, Javier (2000). «Del parateatro litúrgico al teatro religioso: sobre la práctica escénica de Origen, pérdida y restauración de la Virgen del Sagrario de Calderón», en Javier Aparicio Maydeu (ed.), Estudios sobre Calderón. Madrid: Istmo, vol. 2, pp. 744-759.

Apolodoro (1985). Biblioteca mitológica. Javier Arce (intr.) y Margarita Rodríguez de Sepúlveda (trad.). Madrid: Gredos.

Bances Candamo, Francisco Antonio de (2012). El vengador de los cielos y rapto de Elías. Tesis doctoral inédita. Pamplona, Universidad de Navarra.

Calderón de la Barca, Pedro (1989). La fiera, el rayo y la piedra. Aurora Egido (ed.). Madrid: Cátedra.

Calderón de la Barca, Pedro (1992). El divino Jasón. Ignacio Arellano y Ángel L. Cilveti (ed.). Pamplona / Kassel: Universidad de Navarra / Reichenberger.

Calderón de la Barca, Pedro (2007a). «Origen, pérdida y restauración de la Virgen del Sagrario», en Santiago Fernández Mosquera (ed.), Segunda parte de comedias. Madrid: Fundación José Antonio de Castro, pp. 479-557.

Calderón de la Barca, Pedro (2007b). «Los tres mayores prodigios», en Santiago Fernández Mosquera (ed.), Segunda parte de comedias. Texto de la loa y la comedia. Madrid: Fundación José Antonio de Castro, pp. 989-1125.

Calvo, Florencia (2002). «Origen, pérdida y restauración de la Virgen del Sagrario: un modelo dramático abandonado», en Melchora Romanos y Florencia Calvo (eds.), El gran teatro de la historia: Calderón y el drama barroco. Buenos Aires: Universidad de Buenos Aires, pp. 119-133.

Cristóbal, Vicente (2003). «Pigmalión y la estatua: muestras de un tema ovidiano en la poesía española», Cuadernos de Filología Clásica [en línea]. 23.1, pp. 63-87. http://revistas.ucm.es/ index.php/CFCL/article/view/CFCL0303230063A [ref. de 7 de octubre de 2014]

Cubillo de Aragón, Álvaro (2014). Los triunfos de san Miguel. Maribel Martínez López (ed.). Vigo: Academia del Hispanismo.

Egido, Aurora (1989a). «Dos variantes escenográficas de La fiera, el rayo y la piedra de Pedro Calderón de la Barca (según la versión de Vera Tassis, 1687 y la valenciana de 1690)», en Cristóbal Cuevas (ed.), Sobre lírica y teatro. Cinco investigaciones de literatura española. Málaga: UNED, pp. 75-93.

Egido, Aurora (1989b). «Introducción», en Pedro Calderón de la Barca, La fiera, el rayo y la piedra. Aurora Egido (ed.). Madrid: Cátedra, pp. 17-104.

Egido, Aurora (1995). «La fiera, el rayo y la piedra: su puesta en escena según la edición de 1664», en Aurora Egido, El gran teatro de Calderón. Personajes, temas, escenografía. Kassel: Reichenberger, pp. 235-262. [Después aparecido en: Javier Aparicio Maydeu (ed.) (2000). Estudios sobre Calderón. Madrid: Istmo, vol. 2, pp. 693-724.] 
Fernández Mosquera, Santiago (2006). «Libertad hermenéutica y modernidad: las primeras fiestas cortesanas de Calderón», en Odette Gorsse y Frédéric Serralta (coords.), El Siglo de Oro en escena. Homenaje al profesor Marc Vitse. Toulouse: Presses Universitaires du Mirail / Consejería de Educación de la Embajada de España en Francia, pp. 263-282.

Fernández Mosquera, Santiago (2007). «Introducción», en Pedro Calderón de la Barca, Segunda parte de comedias. Madrid: Fundación José Antonio Castro, pp. IX-XCVIII.

Fernández Mosquera, Santiago (2008). «El significado de las primeras fiestas cortesanas de Calderón de la Barca», en Manfred Tietz y Gero Anrscheidt (coords), Calderón y el pensamiento ideológico y cultural de su época. XIV Coloquio Anglogermano sobre Calderón (Heidelberg, 24-28 de julio de 2005). Stuttgart: Franz Steiner, pp. 209-232.

Hoz, Javier de (1988). «Observaciones sobre la materia mitológica en Calderón», en Alberto Navarro González (ed.), Estudios sobre Calderón. Actas del Coloquio calderoniano (Salamanca, 1985). Salamanca: Universidad de Salamanca, pp. 51-59.

Lobato, María Luisa (2001). «Calderón en los sitios de recreación del Rey: esplendor y miserias de escribir para palacio», en Felipe B. Pedraza Jiménez, Rafael González Cañal y Elena E. Marcello (eds.), Calderón: sistema dramático y técnicas escénicas. XIII Jornadas de Teatro Clásico (Almagro, 11, 12 y 13 de julio de 2000) [en línea]. Cuenca: Universidad de Castilla-La Mancha, pp. 187-224. www.uclm.es/centro/ialmagro/publicaciones/pdf/CorralComedias/11_2000/10.pdf [ref. de 7 de octubre de 2014]

Lobato, María Luisa (2003). «Calderón escenógrafo: apuntes a un sistema dramático», en Enrica Cancelliere (ed.), Giornate Calderoniane. Calderón 2000. Atti del Convegno Internazionale (Palermo, 14-17 dicembre 2000). Palermo: Flaccovio, pp. 201-216.

Marcello, Elena E. (2004). «De Valdivielso a Calderón: Origen, pérdida y restauración de la Virgen del Sagrario», Criticón. 91, pp. 79-91.

Martínez Iniesta, Bautista y Juan B. Martínez Bennecker (2009). «Dos mitos griegos en Lope y Calderón», Espéculo [en línea]. 41, s. p. http://www.ucm.es/info/especulo/numero41/ dosmitos.html [ref. de 7 de octubre de 2014]

Moraleda, Pilar (1988). «El mito de Perseo en Lope y Calderón», en Francisco Ruiz Ramón (coord.), El mito en el teatro clásico español. VII Jornadas de Teatro Clásico Español (Almagro, 25 al 27 de septiembre, 1984). Madrid: Taurus, pp. 262-269.

Neumeister, Sebastian (2000). Mito clásico y ostentación. Los dramas mitológicos de Calderón. Edición revisada del original: Mythos und Repräsentation. Die mythologischen Festspiele Calderóns. München: Wilhelm Fink, 1978. Kassel: Reichenberger.

Ocaña, Diego de (2010). Viaje por el Nuevo Mundo: de Guadalupe a Potosí, 1599-1605. Blanca López de Mariscal y Abraham Madroñal (eds.). Madrid / Frankfurt: Iberoamericana / Vervuert.

Ovidio (2005). Metamorfosis. Consuelo Álvarez y Rosa Mª Iglesias (ed. y trad.), $7^{\text {a }}$ ed. Madrid: Cátedra.

Profeti, Maria Grazia (2008). «La comedia de santos entre encargos, teatro comercial y texto literario», en Felipe B. Pedraza Jiménez, Rafael González Cañal y Elena E. Marcello (eds.), La comedia de santos. Coloquio Internacional (Almagro, 1, 2 y 3 de diciembre de 2006). Cuenca: Universidad de Castilla-La Mancha, pp. 233-253.

Rodríguez López-Vázquez, Alfredo (2011). «Estudio introductorio», en Luis Vélez de Guevara, Los tres portentos de Dios. Newark: Juan de la Cuesta, pp. 13-57.

Romanos, Melchora (1998a). «La estructura dramática de la comedia histórica en el LopepreLope. El caso de la comedia trilogía», en Ysla Campbell (ed.), El escritor y la escena VI. Estructuras teatrales de la comedia. Estudios sobre teatro español y novohispano de los Siglos de Oro. Ciudad Juárez: Universidad Autónoma de Ciudad Juárez, pp. 205214.

Romanos, Melchora (1998b). «La dramatización de la temporalidad en dos comedias históricas de Lope de Vega», en M. ${ }^{a}$ Cruz García de Enterría y Alicia Cordón Mesa (eds.), 
Actas del IV Congreso de la Asociación Internacional Siglo de Oro (Alcalá de Henares, 22-27 de junio de 1996). Alcalá de Henares: Universidad de Alcalá de Henares, vol. 2, pp. 1407-1413.

Rubiera, Javier (2013). "'De un efeto dos venganzas": capa y espada en la comedia de santos calderoniana», Anuario Calderoniano. 6, pp. 229-242.

Rull, Enrique (2005). «Puesta en escena y sentido en el teatro mitológico de Calderón: Los tres mayores prodigios», en C. Mata Induráin y M. Zugasti (eds.), Actas del congreso «El Siglo de Oro en el nuevo milenio». Pamplona: Eunsa, vol. 2, pp. 1529-1542.

Rull, Enrique (2012). «Jasón divino y humano», en Carmen Pinillos (ed.), Ingenio, teología y drama en los autos sacramentales de Calderón. Pamplona / Kassel: Universidad de Navarra / Reichenberger, pp. 151-164.

Sáez, Adrián J. (2013). «El niño diablo de Vélez de Guevara y algunas comedias de Calderón (artículo-reseña)», Criticón. 117, pp. 209-219.

Sánchez Escribano, Federico y Alberto Porqueras Mayo (1972). Preceptiva dramática española del Renacimiento y el Barroco. Madrid: Gredos.

Suárez Miramón, Ana (2011). «El viaje marítimo del mercader en los autos de Calderón», en Ignacio Arellano y Juan M. Escudero (coords.), Teología y comedia en Calderón. Anuario Calderoniano. 4, pp. 349-363.

Ulla Lorenzo, Alejandra (2007). «Notas para una edición crítica de Origen, pérdida y restauración de la Virgen del Sagrario, de Pedro Calderón de la Barca», en Antonio César Morón y José Manuel Ruiz Martínez (eds.), En Teoría, hablamos de Literatura. III Congreso Internacional de ALEPH (Granada, del 3 al 7 de abril de 2006). Granada: Dauro, pp. 506-513.

Ulla Lorenzo, Alejandra (2008). «La labor editorial de Vera Tassis en la Segunda parte de Calderón: el ejemplo de Origen, pérdida y restauración de la Virgen del Sagrario», en Lectores, editores y audiencia. La recepción en la literatura hispánica. IV Congreso Internacional de ALEPH (Universitat Autònoma de Barcelona del 2 al 4 de mayo de 2007). Vigo: Academia del Hispanismo, pp. 506-513.

Valbuena-Briones, Ángel (1980). «La primera «comedia» de Calderón», en Alan M. Gordon, Rafael Lapesa y Evelyn Rugg (coords.), Actas del Sexto Congreso Internacional de Hispanistas (Toronto, 22 al 26 de agosto de 1977). Toronto: University of Toronto, pp. 753-756.

Valbuena Prat, Ángel (1989). «Una metodología para precisar los textos de la Segunda parte de comedias de Calderón», en Francisco Mundi Pedret (ed.), Estudios sobre Calderón y el teatro de la Edad de Oro. Homenaje a Kurt y Roswitha Reichenberger. Barcelona: PPU, pp. 39-48.

Vega, Lope de (2011). Arte nuevo de hacer comedias. Evangelina Rodríguez Cuadros (ed.). Madrid: Castalia.

Vega García-Luengos, Germán (2002). «Calderón, nuestro problema (bibliográfico y textual) más aportaciones sobre las comedias de la Segunda parte», en José M. ${ }^{a}$ Ruano de la Haza y Jesús Pérez Magallón (eds.), Ayer y hoy de Calderón. Actas seleccionadas del Congreso Internacional celebrado en Ottawa del 4 al 8 de octubre del 2000. Madrid: Castalia, pp. 37-62.

Vélez de Guevara, Luis (2011). Los tres portentos de Dios. William R. Manson y C. George Peale (eds.) y Alfredo Rodríguez López-Vázquez (intr.). Newark: Juan de la Cuesta.

Virués, Cristóbal de (2003). La gran Semíramis. Elisa Dido. Alfredo Hermenegildo (ed.). Madrid: Cátedra. 